http://jmscr.igmpublication.org/home/ ISSN (e)-2347-176x ISSN (p) 2455-0450 crossref DOI: https://dx.doi.org/10.18535/jmscr/v8i4.35

\title{
Etioclinical Profile of Urinary Tract Infection in Children
}

\section{Dr Susanta Kumar Ghosh ${ }^{1}$, Dr Santosh Kumar Saha ${ }^{2 *}$, Dr Milia Islam ${ }^{3}$}

${ }^{1}$ Associate Professor, Department of Pediatrics, Medical College for Women and Hospital, Uttara, Dhaka, Bangladesh

${ }^{2}$ Assistant Professor (Pediatric Cardiology), National Institute of Cardiovascular Diseases, Dhaka, Bangladesh

${ }^{3}$ Assistant registrar, Department of Pediatric, Medical College for Women and Hospital, Uttara, Dhaka, Bangladesh

*Corresponding Author

Dr Susanta Kumar Ghosh

\begin{abstract}
Objective: In this study our main objective is to assess etioclinical profile of urinary tract infection in children.

Method: This observational study was carried out Tertiary medical college, Dhaka from January 2017 to December 2019 among 100pediatric patients with UTI who attending outpatient and inpatient departments of in department of pediatric. Data were compiled and appropriate statistical package for social science (SPSS). P value $<0.05$ was taken as minimum level of significance.

Results: In this study, most of the patients belong to 1-5 years age group and 69\%and female were 38\% higher than male. Also, $75 \%$ positive culture of bacteriuria was found in female and most of the patients from rural and only $41 \%$ patients treated with antibiotic.

Conclusion: From our study, we can say that E. coli is the most common uropathogen. Antibiotics such as amoxycillin, amoxiclav, cephradine and cefixime. have limited value for the treatment of UTI. Routine observing of susceptibility patterns is necessary, which will help in the empirical treatment of UTI to the clinicians and also for the planning of antibiotic policy of the individual foundation.

Keywords: Urinary tract infections (UTI), antibiotic resistance, amoxicillin.
\end{abstract}

\section{Introduction}

Urinary tract infections (UTI) are the most common infections in world. Reported rates of urinary tract infection (UTI) in children consulting for any acute condition varies widely from $2 \%$ $20 \%$ depending on setting and inclusion criteria. ${ }^{1,2}$ UTI implies presence of actively multiplying organisms in the urinary tract. ${ }^{3}$ UTI occurs in 3$5 \%$ of girls and $1 \%$ of boys during childhood. ${ }^{4}$ The patient with UTI in early infancy presents with abnormal crying, malodorous urine, vomiting, diarrhea and jaundice. Urinary pathogens have shown a changed configuration of susceptibility to antibiotics, resulting in an increase in resistance to commonly used antibiotics.

In modern medicine bacterial infection resistance to antibiotics is one of the most challenging global health threats. It has been assessed that by 2050 , 10 million lives per year will be at risk from antibiotic-resistant infections. Urinary tract infection is a major public health problem in terms of morbidity and treatment cost which affecting 150 million people each year. It also characterizes the most common antibiotic-resistant infections in major care setting. It is a principal cause of 
repeated physician consultations and antibiotic resistance and problem for clinicians in choosing suitable antibiotic.

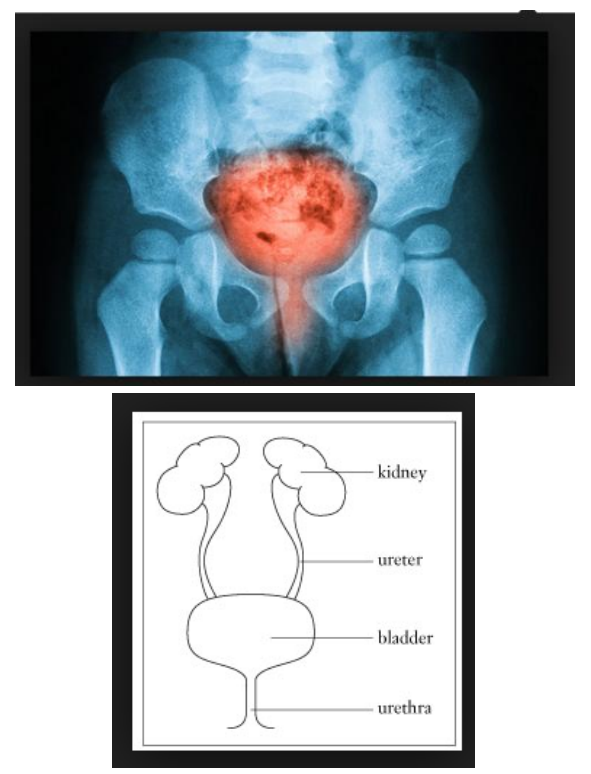

Figure-1: Bacterial Formation in UTI in patients and Urinary structure.

In this study our main objective is to assess etioclinical profile of urinary tract infection in children.

\section{Objective}

\section{General Objective}

$>$ To estimate assess the etioclinical profile of urinary tract infection in children

\section{Specific Objective}

$>$ To identify the frequency of presence culture positive bacteriuria in relation to gender of patient.

To evaluate the incidence of isolation of organism in relation to gender of patient.

\section{Methodology}

Type of study $\mid$ Observational study

\begin{tabular}{l|l}
\hline Place of study & Tertiary medical college, Dhaka \\
\hline Study period & January 2017 to December 2019 \\
\hline Study & $\begin{array}{l}100 \text { pediatric patients with UTI } \\
\text { population }\end{array}$ \\
$\begin{array}{l}\text { attending outpatient and } \\
\text { inpatient departments of in } \\
\text { department of pediatric }\end{array}$ \\
\hline
\end{tabular}

\begin{tabular}{l|l}
\hline $\begin{array}{l}\text { Sampling } \\
\text { technique }\end{array}$ & Purposive \\
\end{tabular}

\section{Method}

All the pediatric patients included in this study were above 2 months of age, presented with the suspected UTI (dysuria, frequency, fever and pain in lower abdomen). Patients on antibiotic were advised to stop antibiotic for 48 hours and were included in this study. Data were collected by a semi structured questionnaire. Clinical history was taken, physical examination was done and recorded in patients' data collection sheet.

\section{Statistical Analysis}

The results are given as Mean \pm SD for the seven independently performed experiments. Unpaired student's " $t$ " test was used to see the level of significance. $\mathrm{P}$ value $<0.05$ was considered statistically significant. ANOVA test was used to see the level of significance among comparison more than two groups, $\mathrm{p}$ value $<0.05$ was considered statistically significant. Data were compiled and appropriate statistical package for social science (SPSS). $\mathrm{P}$ value $<0.05$ was taken as minimum level of significance.

\section{Results}

In table-1 shows age distribution of the patients where most of the patients belong to 1-5 years age group. The following table is given below in detail:

Table-1: Age distribution of the patients

\begin{tabular}{|l|c|}
\hline Age group & $\%$ \\
\hline 2 months to 1-year age group & $10 \%$ \\
\hline 1 to 5 years age group & $51 \%$ \\
\hline 6 to 10 years age group & $17 \%$ \\
\hline$>10$ years age group & $22 \%$ \\
\hline Total & $100 \%$ \\
\hline
\end{tabular}

In figure-2 shows gender distribution of the patients where most of the patients were female, $69 \%$ which was $38 \%$ higher than male. The following figure is given below in detail: 


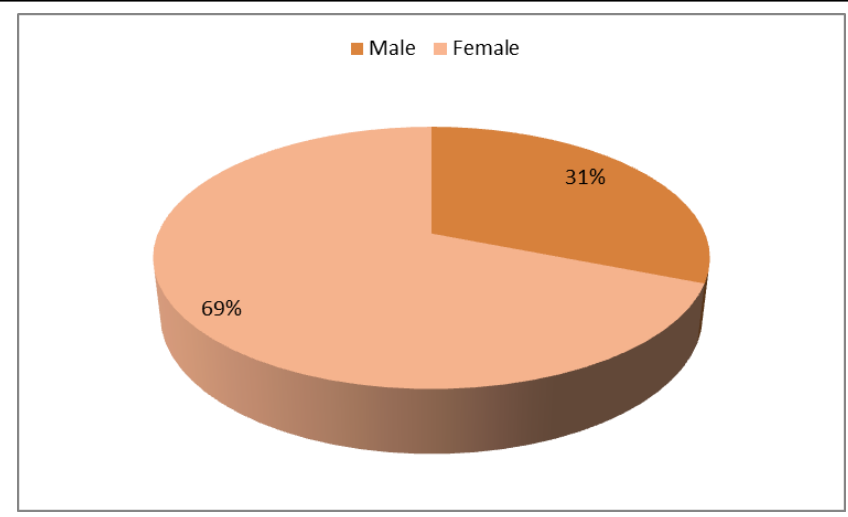

Figure-2: Gender distribution.

In figure-3 shows Frequency of presence culture positive bacteriuria in relation to gender of patient where $75 \%$ positive culture of bacteriuria was found in female. The following figure is given below in detail:

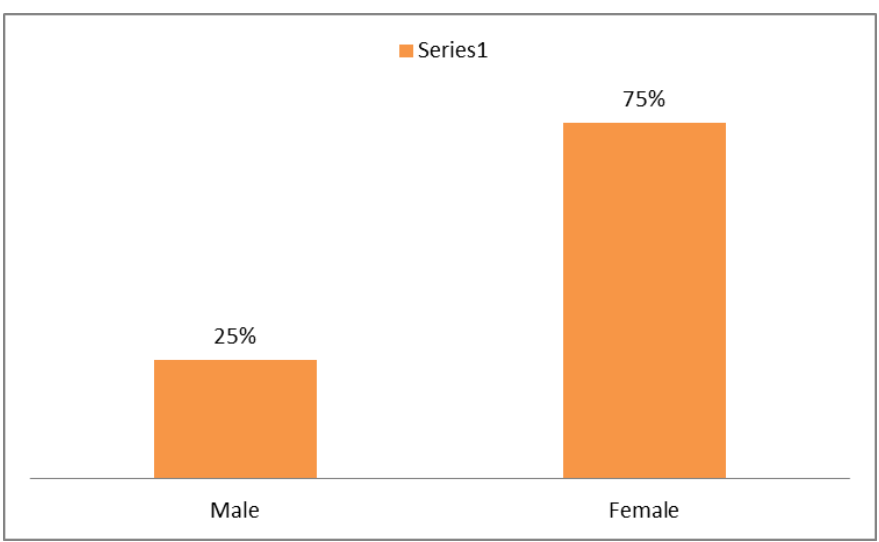

Figure-3: Frequency of presence culture positive bacteriuria in relation to gender of patient.

In table-2 shows demographic characteristics of the CT-UTI patients where most of the patients from rural and only $41 \%$ patients treated with antibiotic. The following table is given below in detail:

Table-2: Demographic characteristics of the CTUTI patients.

\begin{tabular}{|l|c|}
\hline Demographic characteristics & $\mathbf{\%}$ \\
\hline Living area: & \\
Urban & $12 \%$ \\
Rural & $88 \%$ \\
\hline Clinical symptom: & \\
Fever & $57 \%$ \\
Dysuria & $71 \%$ \\
Urgency & $48 \%$ \\
Abdominal pain & $36 \%$ \\
\hline Treated with antibiotics & \\
Yes & $41 \%$ \\
No & $59 \%$ \\
\hline
\end{tabular}

In table-3 shows radiological finding in UTI where among children, only (25\%) had abnormal USG finding (33.3\%) had abnormal MCUG. The following table is given below in detail:

Table-3: Radiological finding in UTI

\begin{tabular}{|l|c|c|}
\hline Investigation & NORMAL & ABNORMAL \\
\hline USG & $75 \%$ & $25 \%$ \\
\hline MCUG & $66.70 \%$ & $33.30 \%$ \\
\hline
\end{tabular}

In figure-4 shows incidence of Isolation of organism in relation to gender of patient where both male and female E. coli was ranked highest $41 \%$ and $43 \%$ among other isolated samples. The following figure is given below in detail:

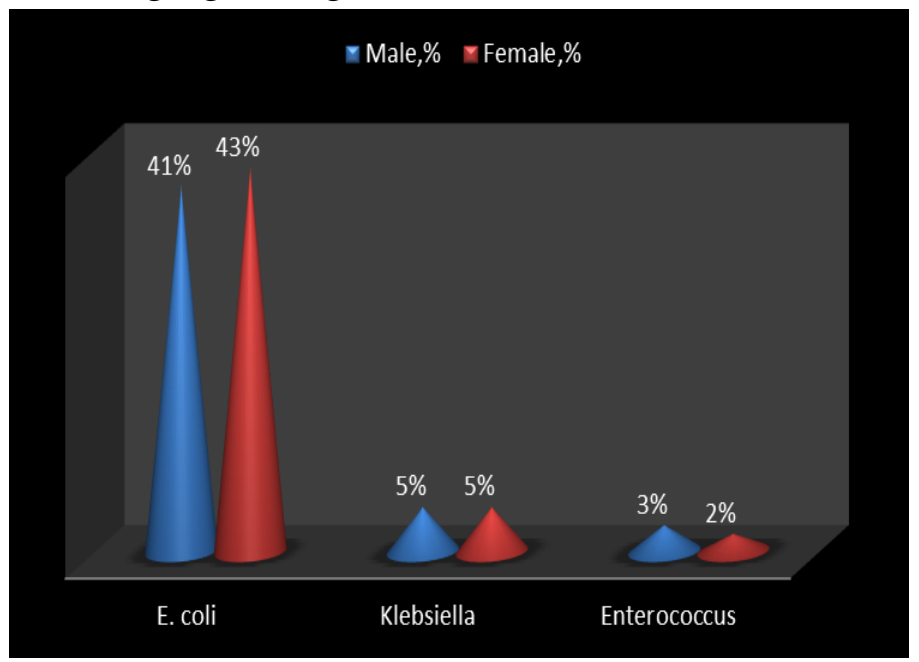

Figure-4: Incidence of Isolation of organism in relation to gender of patient

In table-4 shows In vitro antibiotics resistance pattern of the bacteria where high degree of resistance against commonly used antibioticsamoxycillin, amoxiclav, cephradine and cefixime. The following table is given below in detail:

Table-4: In vitro antibiotics resistance pattern of the bacteria

\begin{tabular}{|l|c|c|}
\hline Name of antibiotics & Total no sensitive & $\%$ \\
\hline Meropenem & 1 & $0.5 \%$ \\
\hline Imipenem & 2 & $1 \%$ \\
\hline Amikacin & 2 & $1 \%$ \\
\hline Tazobactum & 1 & $.5 \%$ \\
\hline Gentamycin & 23 & $12 \%$ \\
\hline Nitrofurantoin & 20 & $10 \%$ \\
\hline Mecillium & 84 & $47 \%$ \\
\hline Colistin & 31 & $16 \%$ \\
\hline Ceftriaxone & 91 & $47 \%$ \\
\hline Cefixime & 130 & $60 \%$ \\
\hline Amoxiclav & 118 & $66 \%$ \\
\hline Amoxicillin & 91 & $47 \%$ \\
\hline
\end{tabular}




\section{Discussion}

This study determines the distribution and antibiotic resistance pattern of bacteria isolated from patients with UTI from a tertiary care center. In our study, only $75 \%$ female had culture positive in patients with UTI symptoms which was similar to other study. ${ }^{6}$ Higher occurrence of UTI in females $(75 \%)$ than in males which is similar to other reports. ${ }^{7,8}$ It was because of anatomical and physical factors. ${ }^{9}$

E. coli majority isolated organism which was expressively higher ( $p$ value was <0.01) than previous studies. Probable cause of this prevalence of intestinal bacteria was due to antibiotic therapy for treating infections outside the urinary tract which contaminate the urinary tract. $^{10}$

Bacteria demonstrations higher degree of resistance against most of the continuing antibiotics used for sensitivity due to irrational consumption of most of the antibiotics during the past decade in our region. ${ }^{11}$

Resistance to amikacin is only $1 \%$ and it is cheap, so it is wise to use it as parental empirical antibiotics in UTI.

Resistance was suggestively increased in resistance pattern in year 2016 for ceftriaxone, and amoxiclav possibly because random use of these antibiotics with insufficient dose and period which is a public health concern in Bangladesh. ${ }^{12}$

According to guideline by Infectious Diseases Society of America (IDSA) in the year 2011, an antibiotic is no longer suggested for empirical treatment of acute UTI if there is $>20 \%$ resistance occurrence to that specificantibiotic. ${ }^{11}$

The antibiotics displays resistance more than $20 \%$ are according to this guideline of IDSA, most of the antibiotics used in our study should not be used for experiential treatment of acute UTI.

In our country there is crucial need of constant monitoring with culture and sensitivity outline of specific pathogens in different health care center. Community awareness program should be started for adherence to treatment protocol considering bacterial resistance and emerging multidrug resistant strains. It is essential to conduct a regional research on the culture and sensitivity patterns of the bacteria.

\section{Conclusion}

From our study, we can say that E. coli is the most common uropathogen. Antibiotics such as amoxycillin, amoxiclav, cephradine and cefixim have limited value for the treatment of UTI. Routine observing of susceptibility patterns is necessary, which will help in the empirical treatment of UTI to the clinicians and also for the planning of antibiotic policy of the individual foundation.

\section{References}

1. Sobel JD, Kaye D. Urinary tract infections. In: Mandell GL, Bennett JE, Dolin R, editors. Principles and Practice of Infectious Diseases. 5th ed. Philadelphia: Churchill Livingstone; 2000. pp. 773-805. [Google Scholar]

2. Naveen R, Mathai E. Some virulence characteristics of uropathogenic Escherichia coli in different patient groups. Indian J Med Res. 2005;122:1437. [PubMed] [Google Scholar]

3. Wilkie ME, Almond MK, Marsh FP. Diagnosis and management of urinary tract infection in adults. BMJ. 1992;305:113741. [PMC free article] [PubMed] [Google Scholar]

4. Bajaj JK, Karyakarte RP, Kulkarni JD, Deshmukh AB. Changing aetiology of urinary tract infections and emergence of drug resistance as a major problem. J Commun Dis. 1999;31:181-4. [PubMed] [Google Scholar]

5. Magalit SL, Gler MT, Tupasi TE. Increasing antimicrobial resistance patterns of community and nosocomial uropathogens in Makati Medical Center. Philipp J Microbiol Assoc. 2001;51:94100. [Google Scholar] 
6. M I Majumder, T Ahmed, D Hossain, S Begum. Bacteriology and antibiotic sensitivity patterns of urinary

7. tract infections in a tertiary hospital in Bangladesh. Mymensingh Med J. 2014; 23 (1): 99-104. PMid:24584381

8. García-Morúa A, Hernández-Torres A, Salazar-de-Hoyos JL, Jaime-Dávila R, Gómez- Guerra LS.

9. Community acquired urinary tract infection etiology and antibiotic resistance in a Mexican population group. Revista Mexicana de Urología. 2009; 69: 45-48.

10. Boucher HW, Talbot GH, Bradley JS. Bad bugs, no drugs: no ESKAPE! An update from the Infectious Diseases

11. Society of America. Clinical Infectious Diseases. 2009; 48(1): 1-12.

12. Khan AU, Musharraf A. Plasmid mediated multiple antibiotic resistance in $P$. mirabilis isolated from the UTI patients. Medical Sci Mon. 2004; 10: 598-602.

13. Chin TL, Mac Gowan AP, Bowker KE. Prevalence of antibiotic resistance in Escherichia coli isolated from urine samples routinely referred by general practitioners in a large urban centre in South-west England. J Anti microb Chemother. 2015; 70: 2167-9.

14. Udur G. Drug resistant cholera in India attributed to antibiotic misuse. BMJ. 2000; 321: 1368-1369. 